\title{
Political Settlements and the Design of Technology Policy
}

\begin{abstract}
Mushtaq H. Khan
(in Stiglitz, Joseph, Justin Yifu Lin and Ebrahim Patel (eds) The Industrial Policy Revolution II. Africa in the Twenty-First Century, London: Palgrave 2013. pp. 243-80)

Technology policies have a dual character. They are technical instruments for addressing important contracting failures affecting technology acquisition and at the same time they are interventions that inevitably create new sources of incomes or rents. These two aspects of technology policies are closely related because the intensity and effectiveness of the rent-seeking strategies of different organizations can explain why particular technology policies are effective or ineffective. One of the puzzles in global comparisons of the performance of technology policies is that policies that worked well in one context fared less well in others, and policies with apparently inferior design characteristics worked better in some contexts compared to policies that were more straightforward. We can make sense of these paradoxes by examining the policies in question in the context of the organizations affected by the policy. The 'political settlement' is our shorthand for describing the distribution of bargaining power and technical capabilities across the relevant organizations in that society. A specific technology policy generates rents across different organizations and requires these rents to be allocated and managed in particular ways to achieve the desired outcomes. The political settlement describing the relative power of different organizations can therefore help to explain why the outcomes of similar policies can vary significantly across contexts. This analysis can also help to design better policies in countries in Africa and Asia that have had mixed experiences with technology policies in the past.
\end{abstract}

In their role as technical instruments, technology policies (or industrial policies) address contracting failures constraining the adoption and learning of new technologies. A variety of factors can prevent investors, financiers, technology providers and firms from privately contracting to transfer new technologies to developing countries. Clearly, the first requirement for a successful technology policy is that the policy should address the specific problem affecting technology acquisition in a country or sector at that time. As there are potentially a number of quite different contracting failures that could affect technology adoption, a policy designed to solve one type of problem may be inappropriate for another. Technology policy can therefore fail if its design does not address the most important problems that are actually constraining technology adoption in that context.

However, even if the policy was technically appropriate it could still fail if it was not effectively implemented and managed. The problem of implementation has been widely recognized, but the problem has been usually explained in terms of a broad binary distinction between the capacities of effective (developmental) states and other ineffective types of states. A common conclusion is that a country without a 
developmental state should not attempt industrial policy, or it should first construct the relevant aspects of a developmental state. Technology policies clearly played an important role in the East Asian success stories of the 1960s and 1970s and yet similar policies achieved less impressive results in many other developing countries. The differences in outcomes can be linked to differences in the degree to which subsidies and support were linked to the achievement of outcomes, with corresponding penalties for non-performance. The East Asian countries undoubtedly had effective developmental states that could discipline subsidy recipients and enforce performance conditions while providing support for technology adoption (Amsden 1989; World Bank 1993; Chang 1994). The problem is that the construction of significant aspects of a similar developmental state is not a feasible goal for most developing countries. If industrial policy requires such a state, and if East Asian technology policies were the only ones that could accelerate technology adoption, most developing countries should indeed refrain from attempting such policies. This is the conclusion of many economists who do not reject the evidence of successful industrial policies in East Asia but who nevertheless believe that such policies may have a negative effect in most other developing countries.

Fortunately, this conclusion may be too pessimistic. To see why, we need to look at the other aspect of industrial policy: its link with rent generation and 'rent-seeking' strategies. The organizations benefiting from technology policy rents can be expected to attempt to capture and protect the streams of income associated with these interventions. However, societies have different configurations of power and capabilities across their economic, political and bureaucratic organizations. As organizations try to capture and protect the rents associated with particular policies, the feasibility of enforcing the conditions that are most likely to yield good results for that policy can vary widely across societies as the relative power of the relevant organizations is different. Thus, the results achieved will depend on the 'fit' between the particular policy (and specifically the rent allocation and management that it requires) and the organizational configuration in which it is placed. The 'developmental state' describes a particular configuration of power between political, bureaucratic and economic organizations (a particular political settlement) and this allowed the enforcement of a range of ambitious industrial policy instruments. In South Korea in particular, significant rents were allocated to large firms across a number of sectors with performance conditions that were credible. Non-performance resulted not only in changes in the relevant policies and the withdrawal of the rents that were not working, but on occasion involved the re-allocation of entire plants to new managements and ownership.

However, countries like India, Bangladesh, Thailand and Malaysia had different configurations of organizational power and capabilities that were significantly different from the East Asian developmental states (as well as being different from each other). Ambitious industrial policies were also tried in these countries but generally produced less dramatic results. Yet these countries also had other variants of industrial policies at different times that were sometimes quite successful in accelerating technology acquisition in particular sectors (Khan 2000b; Khan and Blankenburg 2009; Khan 2013). Different policies were successful because each policy created a different configuration of rents and had different requirements of rent allocation and management. Some policies were therefore more likely to be effective in creating the required combination of incentives and compulsions for technology 
acquisition given the different configuration of organizational power in each country. From a policy point of view, this means that the design of an effective industrial policy has to take into account not just the technical question of the specific contracting failures that have to be addressed. It also has to account for the specific 'political settlement' in the country because only interventions whose success depends on rents being allocated and managed in ways that are feasible in that context are likely to achieve desirable outcomes. Section 1 discusses the most important contracting failures that technology policies have to address. Section 2 locates the problem of policy design in the context of specific political settlements and the rentseeking strategies of organizations. Section 3 deals with a particular contracting failure that needs to be addressed to ensure that success of technology acquisition in developing countries: the problem of developing organizational capabilities for using new technologies in competitive ways. Section 4 develops an analytical framework showing how effective technology policy design has to take into account the nonlinear relationships of policy variables with the political settlement. The approach is able to explain the variable success of technology policies across countries and suggests a methodology for policy design in developing countries.

\section{Technology Policy and Contracting Failures}

Developing countries face significant constraints and contracting problems that can prevent them from adopting existing technologies. These contracting failures are often the primary impediment to development. Technology policies refer to policies that attempt to overcome or bypass the important contracting failures that may be preventing private parties from contracting to adopt and learn new technologies. Contracting failures occur because technology adoption is subject to a number of externalities and principal-agent problems and private contracting may be unable to overcome these problems, particularly in the governance contexts of developing countries (Khan 2013). These problems include the externality problems affecting investments in workforce skills, externalities facing technology providers bringing new technologies to developing countries when these technologies still enjoy technology rents, externalities facing first movers investing in sectors that may turn out to be competitive, a variety of coordination problems affecting investments across sectors and the principal-agent problems facing investors who want to ensure high levels of effort when they finance learning-by-doing processes. If private contracting fails to find appropriate solutions to these and other problems, policy interventions are required. But policy can only be effective if it targets a relevant problem and targets it adequately. As each problem is different, interventions that are appropriate for solving one type of problem will not work if the underlying problem was a different one.

The importance of designing policy responses so that they address the most important contracting failure is discussed in Khan (2013). Developing countries have used a variety of mechanisms to accelerate technology acquisition, including the protection of domestic markets for infant industries, subsidizing technology acquisition through a variety of implicit and explicit subsidies like subsidies on the cost of credit, export subsidies and tax breaks on investments in new machinery. Each of these instruments provides different types of rents which are associated with solutions to specific contracting failures. However, the actual underlying contracting failure will determine the conditions that need to be established for different stakeholders if desirable results are to be achieved. For instance, if positive externalities were preventing adequate 
investments in training, subsidies to firms would have to come with arrangements for monitoring the quality of training, and the terms of the rent allocation would have to include credible withdrawal and penalty arrangements if the training was poor (Dosi 1988; Khan 2000a). A very different technology problem emerges if external technology providers feel their technology rents are threatened by illegal imitation. If this slows down the inflow of technologies into the country, the appropriate policy response may be to protect the rents of technology owners through patents or to provide them with compensating rents in the form of incentives or licensing fees. In each case a different set of conditions need to be established on the relevant rents. For instance, if incentives are provided to technology providers, the quality and type of technologies they transfer have to be monitored, including the pace of subcontracting to domestic producers. In the case of patents, regulatory agencies have to have the capability to enforce these restrictions but also to negotiate the time period of patent protection for each sector to maximize the net benefit for that society (Hoekman, et al. 2004). In reality, patent protection terms are often determined by more advanced countries and these terms do not necessarily protect the interests of developing countries (Khan 2000a; Stiglitz 2007).

The first mover problem refers to the possibility that the first investors in a sector may discover that the country has a comparative advantage in that sector but may fail to capture sufficient benefits themselves to justify the costs and risks of their investments in discovery (Hausmann and Rodrik 2003). The discovery of new business opportunities obviously has positive externalities for the country but the initial investors may not be able to capture much of this. Moreover, subsequent entry into the sector can actually reduce their profits by raising wages and input costs. Unlike new innovations, discovery cannot be patented, and therefore the solution to this contracting failure may require temporary subsidies that encourage trials in new sectors. These rents need their own set of effective conditions: they have to be available for short periods, no longer than is needed to set up the trials and discover the presence or absence of comparative advantage in that sector. For this contracting failure, it is critical for the relevant agencies to have the capacity to withdraw rents after fixed periods and in any case to desist from continuing to support experiments that are clearly not going to produce competitive industries.

Coordination of investments may be important because of both demand and supply side complementarities. High transaction costs, information asymmetries and the possibility of opportunistic behaviour by second movers may preclude private contracting solutions to solve coordination problems (Rosenstein-Rodan 1943; Nurkse 1953; Scitovsky 1954; Williamson 1985; Murphy, et al. 1989). Public investments in coordination also provide rents to private providers but here a different set of conditions have to be enforced. Government agencies charged with the implementation of coordination policies are in a position to provide rents to firms in promoted clusters. The identification of the clusters to be supported and the complementary investments that private investors have to provide have to be agreed upon, monitored and enforced.

The solutions to all these contracting failures assume that a more fundamental contracting failure has been addressed. Developing countries typically find it difficult to absorb and use existing technologies even when their wages are low and they have sufficient workers with the appropriate formal skills. The missing factor is the 
organizational capability of the production team. Owners, managers and supervisors do not know how to set up the factory, align the machinery, set up systems for quality control, reduce input wastage and product rejection, manage inventories, match order flows with production cycles, maintain after sales services and a host of other internal coordination and management issues that are essential for achieving competitiveness. As a result, the firm may be able to buy the machinery at international prices, employ the workers and managers at lower wages than the most competitive country, and yet be unable to achieve competitiveness. The development of organizational capabilities requires the acquisition of tacit knowledge through learning-by-doing. By definition, learning-by-doing requires opportunities for doing, and this requires periods of lossfinancing when the firm produces but is unable to make a profit. This period of learning can help to raise organizational capabilities if the production team is also under pressure to continuously experiment with new internal organizational arrangements to raise productivity. Thus, the 'doing' is necessary but does not guarantee learning, unless there is some compulsion on the owners, managers and supervisors to put in high levels of effort in the learning process (Khan 2013).

In theory, sufficiently complex contingency contracts between the private parties involved could address these requirements, but their enforcement is not likely to be credible in the typical developing country. Essentially, financiers need to have credible ways of penalizing non-performance and extracting their capital if the project fails. Private contracting of this type typically does not emerge because financiers cannot credibly ensure that stakeholders within the firm will put in high levels of effort in learning and thereby assure returns on their investments. Technology policy can address this failure by co-financing or sharing the risks involved in the learning provided governance agencies have the appropriate enforcement capabilities to induce appropriate levels of learning effort. The necessary condition for rent allocation here is not just that a firm gets the rent that allows it to engage in learning-by-doing, but also that the conditions of rent withdrawal are clearly set out so that owners, managers, supervisors and others feel the compulsion to put in a high level of effort in the learning process. This problem usually cannot be solved by announcing the time period for support in advance. Unlike a trial that is supposed to discover comparative advantage (and reasonable time periods for trials can be pre-specified), here comparative advantage is being created through learning and the development of organizational capabilities. The creation of comparative advantage can take much longer and the time period may differ from country to country, sector to sector, and perhaps even firm to firm. More complex monitoring and incentives have to be created here to induce the right kinds of effort.

Given the different problems that technology policies may be required to solve, and the very different governance and institutional conditions that each requires, one reason why effective policies cannot have a standard design across countries is simply because they must address different problems and priorities. Without careful attention to identifying the major problems the country faces, and designing the rent monitoring and allocation conditions accordingly, a general policy of supporting infant industries can produce very variable outcomes. In some cases, the requisite conditions for solving the underlying problems could fortuitously be in place, and in others not. In some countries, famously the East Asian ones, ambitious technology policies that provided support simultaneously for many firms and sectors resulted in accelerated technology acquisition and development. In others, similar policies resulted in the 
proliferation of subsidies to protected industries that refused to grow up. Subsidies kept growing and could not be withdrawn despite the poor performance of the supported firms and sectors. Similarly, in some countries, development banks played a dynamic role, while in others they closed down because their low interest loans were not repaid and their bad debts escalated. In the less dynamic cases, consumers and taxpayers paid the price of these failing policies till they were finally abandoned.

The identification of the relevant contracting failure is the first stage of finding an effective solution to a technology acquisition problem. The second stage is to investigate whether a policy with the requisite characteristics can be enforced given the power and capabilities of the organizations affected. Here again there is a degree of openness, but now the openness can create opportunities as well as problems. On the one hand, obvious policy responses that worked in some other country may not be implementable because the configuration of power may be such that the policy would be excessively distorted by rent-seeking activities and desirable outcomes may not emerge. On the other hand, there are typically multiple solutions to the same problem and each solution implies a different allocation of rents and a somewhat different set of conditions for achieving desirable outcomes. This makes it more likely that an effective solution can be found despite differences in the political settlement. The problem of finding a solution to a contracting failure that is effective within a specific political settlement is a general problem that can affect solutions to any contracting failure. We illustrate the general problem with reference to a particular contracting failure: the problem of developing organizational capabilities through learning-bydoing. There is an additional merit in focusing on the learning-by-doing problem. Attempts to solve any of the other problems affecting technology acquisition are likely to fail if effective organizations that can competitively use the new technologies do not yet exist.

\section{Political settlements and Rents}

Rents are defined as incomes higher than the minimum a person or organization would have accepted, the minimum usually being defined as the income in the nextbest opportunity available to that individual or organization. According to this definition, policies that leave some individuals better off create rents for them. However, policies can also leave some individuals worse off, so that in effect they suffer negative rents, though this is not how these losses are usually described in the literature. Taxes for instance leave some individuals worse off, while the corresponding subsidies provide rents for others. Any policy intervention will change income flows and therefore every policy intervention creates rents, both positive as well as negative. In the simple story that is often told in textbooks, in the absence of government intervention a zero-rent general equilibrium is possible and serves as the benchmark for the analysis of rents. This is because if there were no restrictions on entry and exit and all contracts were voluntary, no factor would earn higher or lower returns in any activity than in any alternative activity available to that factor, and consequently no factor could earn a rent or suffer a 'negative rent'. If we ignore the critical question of where the property rights sustaining a general equilibrium came from, and if we ignore the equally critical question of how in the absence of any rents the information required for market operations can be discovered, we can claim that if such an outcome could be achieved by private contracting, we would also achieve an efficient allocation of resources. An efficient allocation of resources is simply one 
where re-allocation cannot enhance net social benefit and this would be the case if no factor was earning a higher or lower return anywhere else. Much of the analysis of rents and rent seeking has been hampered by this unnecessary and unrealistic benchmark. If we accept the general equilibrium benchmark, deviations from this benchmark generate rents and these deviations signal inefficiency.

In reality, as North (1990) and Stiglitz (1996) argue in different ways, the general equilibrium benchmark is not only unrealistic, it can be very misleading as a guide for policy-making. First, in the institutional economics that North introduced, the creation of property rights (for instance over free-access resources) creates rents for owners because these streams of property incomes did not exist earlier. Since the role of the state is transparent when property rights are newly created, new property rights are clearly the product of 'intervention'. The incremental income streams associated with them are therefore the product of intervention and appear as 'rents'. Indeed neoclassical textbooks occasionally describe the income streams that are created when open access natural resources become property as rents. Since the absence of property rights was associated with free access overuse, the creation of property rights and the associated rents are associated with improvements in net social benefits. In fact, free access can destroy the value of any asset, not just natural resources, so the incremental creation of property rights always creates new income streams (rents) and in many cases also enhances net social benefits. Paradoxically, once property rights have existed for some time, mainstream economics overlooks the role of the state in maintaining these property rights, and the income from property of all types is no longer seen as the product of 'interventions' and therefore are no longer rents. The general equilibrium model extends this to the extreme case where property rights have been defined over all possible assets and all these rights are protected at no cost and without a state. Property ownership in itself is no longer perceived to have anything to do with the state and the returns from property ownership are therefore perceived to be quite different from rents that are now only created by interventions that prevent factors from being freely allocated.

In reality, property rights are always imperfectly developed because of the high costs of defining and protecting many rights. There are differences between advanced and developing countries because of differences in the capacities of their states, but the proposition is true in general for all countries. Partly for this reason and partly because of the high costs of contracting due to asymmetric information and other problems, contracting in incomplete markets is also incomplete. In the real world, we are never in general equilibrium and a wide variety of rents exist, some of them associated with past interventions that enhanced net social benefits and others associated with interventions that reduced them. Stiglitz (1996) therefore argues that incremental interventions can potentially raise net social benefit even though they will be associated with the creation of new rents. We can re-state this as follows: The appropriate benchmark for evaluating rents is not the zero-rent general equilibrium that never existed and can never be reached but the currently existing structure of rights, interventions and institutional solutions that defines a complex structure of rents in the economy. The question is whether an incremental intervention that creates an incremental rent is associated with a positive or negative incremental change in net social benefits in this context. Interventions and rents that are associated with positive incremental outcomes are desirable even if they create rents. 
The incremental rents framework should not be confused with an analysis of rents that takes the zero-rents general equilibrium as its benchmark. The alternative framework does not presume either that a general equilibrium is feasible or that movements in that direction are necessarily beneficial. It certainly does not explain rents in terms of market restrictions causing deviations from that (unrealistic) benchmark. Rather, the incremental rents framework seeks to identify and analyse the changes in rents associated with specific policies. These rents identify the direct beneficiaries of a policy so that we can begin to assess the plausibility of subjecting them to the conditions theoretically required for the policy to be effective. The actual outcome of the policy depends on how effectively rent seeking by the organizations benefiting from the rents can prevent or distort the imposition of the conditions that are required for socially desirable outcomes to emerge. The likelihood of that in turn depends on the interests and holding power of the organizations involved, and this information is therefore also required.

We describe the configuration of capabilities and holding powers across organizations as a 'political settlement'. The configuration of organizational power in a society is constantly changing but usually not so rapidly that aspects of continuity cannot be identified. Indeed, there are powerful feedback mechanisms between the distribution of organizational power in one period, the activities of organizations to protect and create institutions and policies to sustain their relative incomes and organizational powers during that period, and the reproduction of organizational power as a result of these activities in the next period. The distribution of organizational capabilities is nevertheless gradually changing but in a path-dependent way, with important aspects of continuity. We describe the currently existing macro-system of organizational capabilities and powers as a political settlement, and at any given time, countries have political settlements with features that are reproducible over time (Khan 2010).

Combining the incremental rent analysis with a description of the political settlement allows us to analyse the likelihood of a particular policy achieving its expected outcomes. If the organizations affected by that policy are likely to operate as the theory expects them to, the expected outcome may be achieved. However, organizations have their own interests and capabilities and they may want to modify the application of the policy. In particular, they may want to modify the conditions under which they gain or lose the incremental rents created by a policy. For this, they are likely to engage in rent-seeking activities of different types. For instance, the organizations in question may find the formal conditions for acquiring rents to be too difficult relative to the alternative of attempting to distort or overcome these conditions using appropriate rent-seeking activities. The strategy they actually follow will depend on how easy it is to modify or resist the imposition of the formal conditions, and that depends on the bargaining power of these organizations relative to the governance agencies of the state. If they have the capability to modify the policy, the expected outcomes would be unlikely to be achieved. Thus, a policy that attempts to make powerful organizations operate in ways that they are likely to successfully resist is likely to either fail or achieve much more limited results.

Figure 1 shows the relationship between a technical analysis of expected outcomes of policy and an analysis of the likely responses of organizations to the rents created by the policy. The 'standard analysis' of policy outcomes describes the technical analysis of policy responses to contracting failures which typically ignores the problem of 
enforcing the conditions required for policy success. This is shown in the shaded rectangle in Figure 1. In theory, policy works by changing the incentives and compulsions of the relevant parties so that more desirable social outcomes can emerge. The changes in incentives and compulsions can be described by the incremental rents that are created by the policy and the conditions that organizations have to fulfil to gain or lose these rents. The vertical chain of causation described as the 'incremental rent analysis' is superimposed on this and asks how the organizations affected by these rents are likely to respond, given their interests and their bargaining power relative to other affected organizations and the agencies enforcing the conditions. The result is that the actual rent allocation may differ from the theoretical expectation and organizations can also modify the conditions under which the relevant rents can be gained or lost. As a result, the actual outcomes achieved may be quite different from the outcomes that are theoretically expected. Moreover, as political settlements vary across countries, the actual outcomes associated with the same policy could be quite different in different contexts.

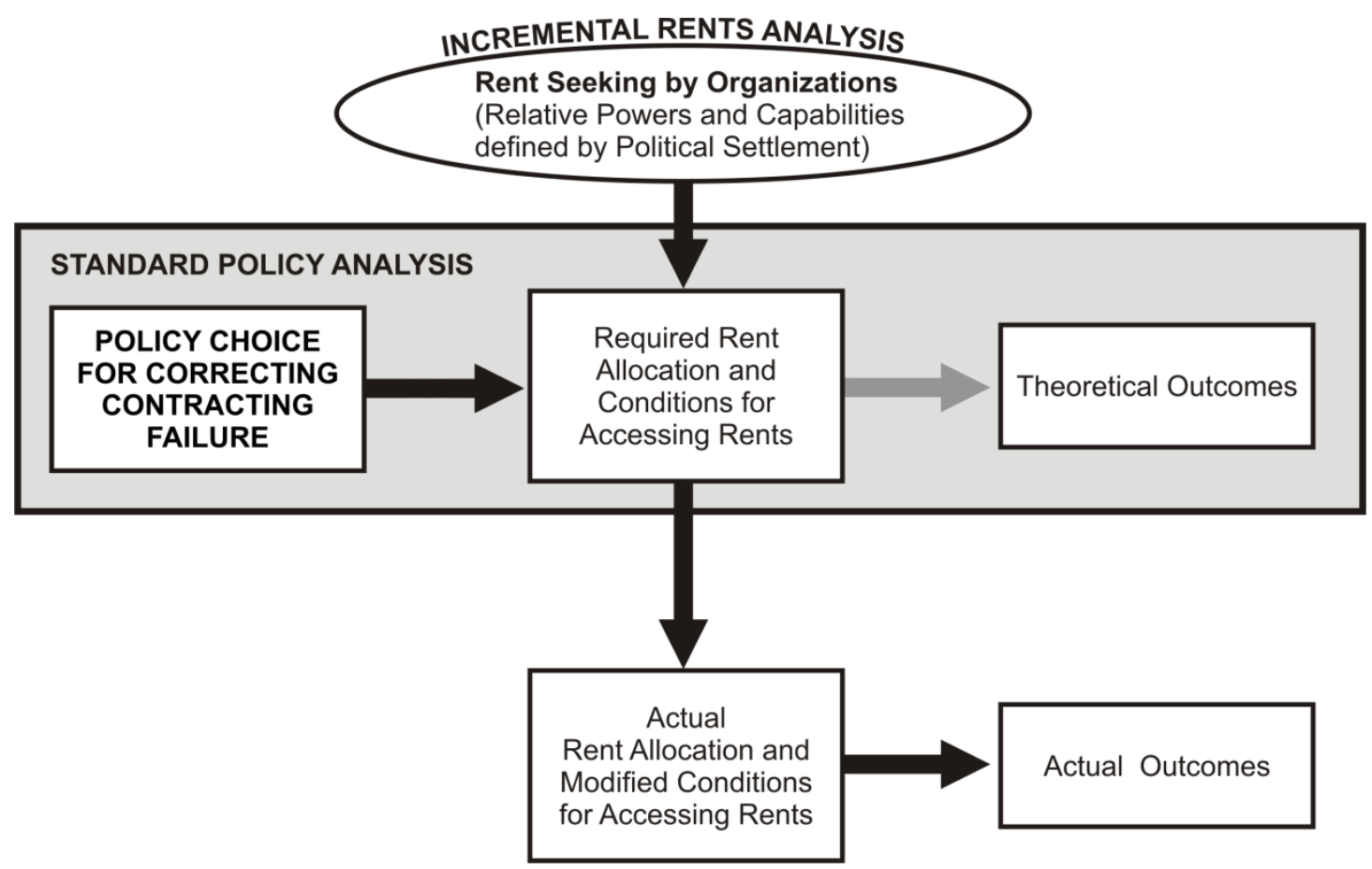

Figure 1 Rents, Political Settlements and Policy Outcomes

These overlapping analytical questions can be illustrated with reference to a simpler set of contracting failures, for instance those that result in persistent pollution externalities. In this case, a number of interventions are possible that could enhance net social benefits for society. One solution to this contracting failure is a tax imposing 'negative rents' on polluters. This can reduce the incentive to pollute and result in higher net social benefits. However, the success of the tax depends on its allocation and management: state agencies have to assess the right tax level, monitor polluting activities, collect the appropriate taxes from polluting organizations, and prevent evasion or the passing on of these costs to others. These are the required rent allocation conditions in this case. Not surprisingly, pollution taxes may not produce the desired outcome and a rent analysis may explain why. An obvious problem may 
be that the theoretical tax allocation and management requirements are not met in practice because the organizations that are polluting can use rent-seeking activities to effectively distort the monitoring of pollution and the collection of taxes. If many polluting organizations have the capability to block the accurate monitoring of their activities, to challenge the tax regime legally, or in developing countries, to buy themselves political or bureaucratic support to block or evade the policy, the actual outcome of the strategy may be far removed from the expected one.

The rent analysis can be extended to policy design and allows us to ask if an alternative policy may have generated better outcomes given the political settlement. In reality, policy choice (the independent variable on the left in Figure 1) is also to some extent the product of the rent-seeking activities of organizations, but to simplify we assume with some realism that policy-makers have sufficient freedom to attempt a number of different types of policy responses to the same problem. For instance, apart from the tax solution, the problem of pollution externalities can be addressed by subsidies or by imposing regulatory restrictions on pollution. Consider the subsidy solution. Instead of taxing polluters, the subsidy strategy offers polluters rewards for reducing pollution. The success of this strategy depends on a very different set of monitoring and enforcement capabilities. Some of the monitoring requirements could be more demanding because the government has to estimate the pollution that would have been created in the absence of the policy, as well as monitoring current pollution to reward polluters for the reduction. Powerful organizations can obviously attempt to influence this assessment in different ways. However, instead of the difficult task of extracting revenue from powerful organizations, the subsidy strategy has the easier task of providing organizations with subsidies.

Given the configuration of power, this strategy may produce better outcomes relative to a tax strategy, provided some minimal conditions linking the delivery of the subsidy to actual pollution reduction could be enforced. This enforcement is more likely if after the subsidy and the pollution reduction the relevant organizations are better off than they would be if they continued polluting. In contrast, in the tax solution, the enforcement of the tax leaves polluting organizations worse off than they were. While enforcement is not likely to be perfect in either case, we would expect enforcement to be better for the subsidy case if the polluting organizations are powerful. The downside of the subsidy strategy is that the government loses revenue, instead of gaining revenue with a tax strategy. In addition, considerations of justice may politically prevent subsidies being offered to polluters, but if the polluters also happen to be relatively poor, welfare considerations could support a subsidy strategy. The general point is that apart from fiscal, justice and other considerations, the alternative policy solutions need to be compared purely in terms of the enforceability of the conditions required to achieve the desired outcomes. Given the distribution of power across organizations described by the political settlement, this comparison could help to identify the policy solution that is most likely to be effective in enhancing net social benefits.

The general proposition that follows from this discussion is that there are typically several policies that could address any particular contracting failure and an important policy question is to select the best policy for that context. Policy choices can be motivated by many considerations, for instance, fiscal consequences or distributive justice, and to some extent policy choices are themselves driven by rent-seeking 
activities of organizations. However, an important consideration for policy-makers is to check that the requirements for successful policy outcomes (the required rent allocation conditions shown in Figure 1) can be plausibly approximated given the political settlement. The relative power of organizations is difficult to influence as this reflects the political settlement describing macro-social characteristics of that society. The political settlement can and does change over time but it is not an immediate policy variable under most circumstances. Normally, the current political settlement is an exogenous variable that may not be amenable to policy choices. This simply means that selecting the policy that is most likely to work in that context is very important for ensuring the best possible policy outcomes.

\section{Technology Policies for Accelerating Learning}

The contracting failures affecting pollution are relatively simple compared to the contracting failures that can affect technology acquisition. As discussed earlier, there are potentially several different types of contracting failures affecting technology acquisition, and the first task is to identify the most important ones affecting particular countries or sectors. We will illustrate the general argument with reference to a particular contracting failure affecting technology acquisition: the problem of financing the learning-by-doing necessary for achieving competitiveness with new technologies (Khan 2013). In developing countries, while domestic innovations may play a role, the main problem of technology acquisition is 'learning' the use of existing technologies and building the organizational capabilities for competitively using these technologies. Developing countries find it difficult to set up productive economic organizations even if they can buy the appropriate machines and have low wages for workers with the appropriate formal skills. Learning refers to processes of learning-by-doing required for building the relevant organizational capabilities so that economic organizations can become competitive in using these technologies and implicit or explicit subsidies are no longer required for these operations.

The core problem of achieving competitiveness with new technologies is that competitiveness is determined not only by domestic factor prices but primarily by the productivity of labour, inputs and of the capital stock of domestic economic organizations using these technologies. These productivities depend largely on the organizational setup of the firm and not just on the quality and vintage of its capital stock and the formal skills of its workforce. The firm as an economic organization has to continue to experiment and adapt its internal organizational structures to reduce costs and improve a range of vital input-output ratios. The processes in question include setting up the machines and processes in the workplace to achieve the fastest throughput of production, setting up internal processes to minimize input wastage, processes to minimize the rate of rejection of final products, to minimize inventories without losing production time due to bottlenecks, maximize orders without missing delivery deadlines, managing customer services and after sales support and so on. These vital processes are much more important and more difficult to learn than the operation of individual pieces of machinery. The knowledge in question is also tacit knowledge that can only be acquired through learning-by-doing processes and not from manuals or classes, though these can provide some threshold level of knowledge. Moreover, the most effective organizational design for using the same technology may also vary across countries, because organizations have to respond to and find solutions to differences in work patterns, infrastructural constraints, external 
supply and support systems and so on. Thus, hiring supervisors with experience in foreign factories can reduce the learning time, but organizational innovation is still necessary because the organizational design of a foreign factory will in most cases not achieve the competitiveness that is required.

The challenge for technology acquisition is therefore to adapt the design of organizations, their internal hierarchy structures, incentive systems, monitoring systems and so on, till competitiveness is achieved. If the development of organizational capability fails, the plant continues to produce at a higher cost or produces products of a lower quality. This can be sustained for a time using market protection and subsidies of different types but subsidies cannot be sustained forever. Moreover, if organizational capability does not develop, the subsidies required to survive are likely to grow as plants in other countries become even more productive. Thus, the failure to develop productive organizational capabilities is likely to result in a failure of the technology acquisition strategy as a whole. The organizational learning problem has two closely related dimensions. First, during the period of learning the organization is not yet competitive and its low or negative profits have to be financed. Secondly, the financing has to be on terms such that the stakeholders within the firm put in high levels of effort in the learning process to rapidly achieve competitiveness. In principle, the loss-making period of learning-by-doing can be financed with injections of private funds, provided the contracts between financiers and firms create sufficient compulsions on the firm to use the learning space to rapidly raise productivity and product quality. The 'doing' is necessary for 'learning', but on its own the doing is not sufficient to ensure learning. This is unfortunately demonstrated by the many instances of 'infant industries' in developing countries that failed to become competitive after years of subsidies financing learning-by-doing.

The important question is why private contracting fails to organize investments in high-effort learning, particularly since all the stakeholders in the firm stand to gain. Several variants of contracting failures can be relevant, and it is important to identify the most plausible ones. One possibility is an appropriability problem. Here the assumption is that a first-mover firm may have an incentive to invest in learning to create a competitive organization because low wages in the country offers the possibility of earning higher-than-normal profits once productivity improves. The appropriability problem is that some of their supervisors and managers can leave with their tacit knowledge to set up competing firms. If these competing firms reduce the profits of the first mover down to the normal level, that can dissuade investments in learning. This is a theoretically plausible argument except that privately financed learning fails to emerge just as frequently in industries and sectors that do not have the characteristics that would make them subject to this type of appropriability problem. For instance, private investments in learning are rare even in sectors with considerable market power or entry barriers, like automobiles or iron and steel in countries which have the formal skills to contemplate these sectors. In addition, at the other end of the scale, there are many sectors like low technology garments in labour surplus countries, where entry does not have any plausible threat of raising wages or global input prices and both first movers and their followers can expect low profit margins to begin with. Here too the fear of entry is unlikely to deter the first mover. On the contrary, in many such industries, including electronic components and light engineering, the first mover may positively welcome new entrants so that clustering happens and foreign buyers are attracted to set up their buying houses. So while the 
appropriability problem for first movers may affect investments in learning in some sectors, it is not likely to be the general problem

If first mover fears of losing profits were the relevant problem, this could be addressed with short-term subsidies for new start-ups. With a temporary subsidy for the learning period, the first mover would not have to finance the development of organizational structures on the expectation of high future profits. In that case, even if imitation was expected to reduce profits to the normal level relatively quickly, the first mover would still earn normal profits like anyone else. However, if investments in learning are not happening even in sectors where entry does not pose compelling risks to future profitability, some other type of contracting failure may be relevant. Indeed, we know that subsidizing the loss-making period is not sufficient for ensuring the achievement of competitiveness because many firms and industries never become competitive even after years of external support. This suggests other contracting failures may be at play. Private financiers may not have any credible way of ensuring that when they finance a firm's loss-making period, decision-makers within the firm will be compelled to put in high levels of effort in the learning process so that competitiveness is rapidly achieved. What type of contract would ensure this?

When a developing country acquires existing technologies, its firms cannot hope for very high profits in the future, irrespective of the level of domestic entry. The technologies are typically mature, there are countries with higher wages producing these products (but with even higher productivity levels they are more competitive), and many lower wage countries could potentially enter later. The expectation of above normal profits cannot be the main incentive for domestic producers attempting to enter these markets, and this is the main reason why focusing on the appropriability problem may be misleading. In the general case, the firm that is successful in organizing learning can at best look forward to normal profits in a harshly competitive world. The prize, in other words, is not very attractive, and certainly in the general case does not offer the promise of significant or long-lasting rents. Yet learning happens in some of these 'normal-profit' sectors with no promise of above-normal profits for first movers, and learning often fails in many sectors despite long-lasting learning rents being allocated to first movers in the form of protected markets and subsidies. The answer to this puzzle must be that normal profits can be incentive enough for many types of learning and the availability of rents on their own is insufficient to ensure successful learning-by-doing. The deeper problem is likely to be one of ensuring high levels of effort in the process of learning within the production team. This is particularly likely to be a problem if the learning is financed by financiers who are not in control of the learning process within the firm.

Consider the simplest case of a firm owned by a single individual who is also the manager. This allows us to ignore the principal-agent problems between owners and managers within the firm. The problem we focus on is that the typical owner is unlikely to have the resources or the risk appetite to finance the entire process of technology acquisition and learning without external financing. The external financier on the other hand has little control over the effort that insiders put into the learning process. Neither side can accurately predict how long it will take the firm to become profitable. Finally, the firm is unlikely to make high profits even when it does become profitable. It follows that in the typical case, it is hard to find a contract acceptable to both sides which provides adequate financing for learning and yet creates strong 
compulsions for putting in high levels of effort. If effort could be easily observed, contracting would be easier. The financier could repeatedly check progress and stick it out despite temporary problems if there was a prospect of a resolution soon. Without this, the financier is likely to demand contracts with exit clauses that allow it to withdraw investments at a later stage if progress is perceived to be slow, but the firm will reject most such contracts if it thinks its effort can go to waste at a later stage because it could not persuade the financier to stick it out for a little longer. Only a relatively complex contract would be acceptable to both sides under these circumstances, but the more complex the contract, the more unlikely that it can be enforced in the typical developing country.

Fixed interest financing will probably not be acceptable to the firm because it exposes it to too much risk. A viable firm engaging in technology acquisition may easily go bankrupt with a fixed interest loan if there were relatively small delays in achieving competitiveness. An ex post profit-sharing contract may be acceptable to the firm if the terms were right. But in most cases profit-sharing may be unacceptable for the external financier given the tight limits that have to be set on the learning period for the financing to be viable. It is possible to imagine contingency contracts that may be acceptable to both sides, for instance, setting clearly defined milestones which could be used to trigger credible exit strategies for the financier enabling at least a part of the investment to be withdrawn under different contingencies. This would reduce the risk for the financier and also increase the compulsion on the firm to put in high levels of effort. However, given the weak contract enforcement conditions in most developing countries, plus the uncertainties of evaluating intermediate learning outcomes (for the financier) and of predicting achievable levels of progress in learning in advance (for the firm), it is not surprising that contingency contracts for financing learning are not often observed in practice.

The technical problem that private contracting can fail to address is summarized in Figure 2. The vertical axis measures the competitiveness of the domestic firm for a product of a specific quality that it intends to produce after acquiring a technology new to the firm and new to the country. Competitiveness is measured by $\frac{P \text { global }}{C_{\text {domestic }}}$ where $P^{\text {global }}$ is the global market price of a product of that quality and $C^{\text {domestic }}$ is the domestic cost of production. The domestic firm becomes competitive only when the competitiveness index becomes greater than 1. At time $t=1$ when the firm plans to acquire its technology, its low productivity of labour and input usage and possibly also low levels of capacity utilization and capital productivity means that its competitiveness index at point $\mathrm{X}$ is far below that required for market viability. For the firm to be able to begin a learning-by-doing process of capability development, the implicit gap in competitiveness has to be covered with loss financing shown in Figure 2 by the gap $s_{Q}$. The contracting problem is that this financing has to be provided by financiers external to the firm on contractual terms acceptable to all parties. If the firm puts in high levels of effort in experimentation and adaptation of its internal organizational routines, the high effort path can lead it to competitiveness by time $t=\mathrm{n}$. If on the other hand the firm puts in low levels of effort in learning, it may never achieve competitiveness (or achieve it too late for the financing to be profitable). The financier cannot predict the firm's level of effort in advance, and may even be unable to discern the effort trajectory while organizational capability is being developed. Given the narrow profit margins in most cases and the sensitivity of the 
returns to the breakeven period, it is not surprising that left to their own devices, financiers with money and firms with potentially good management structures fail to contract to finance the learning required for technology acquisition.

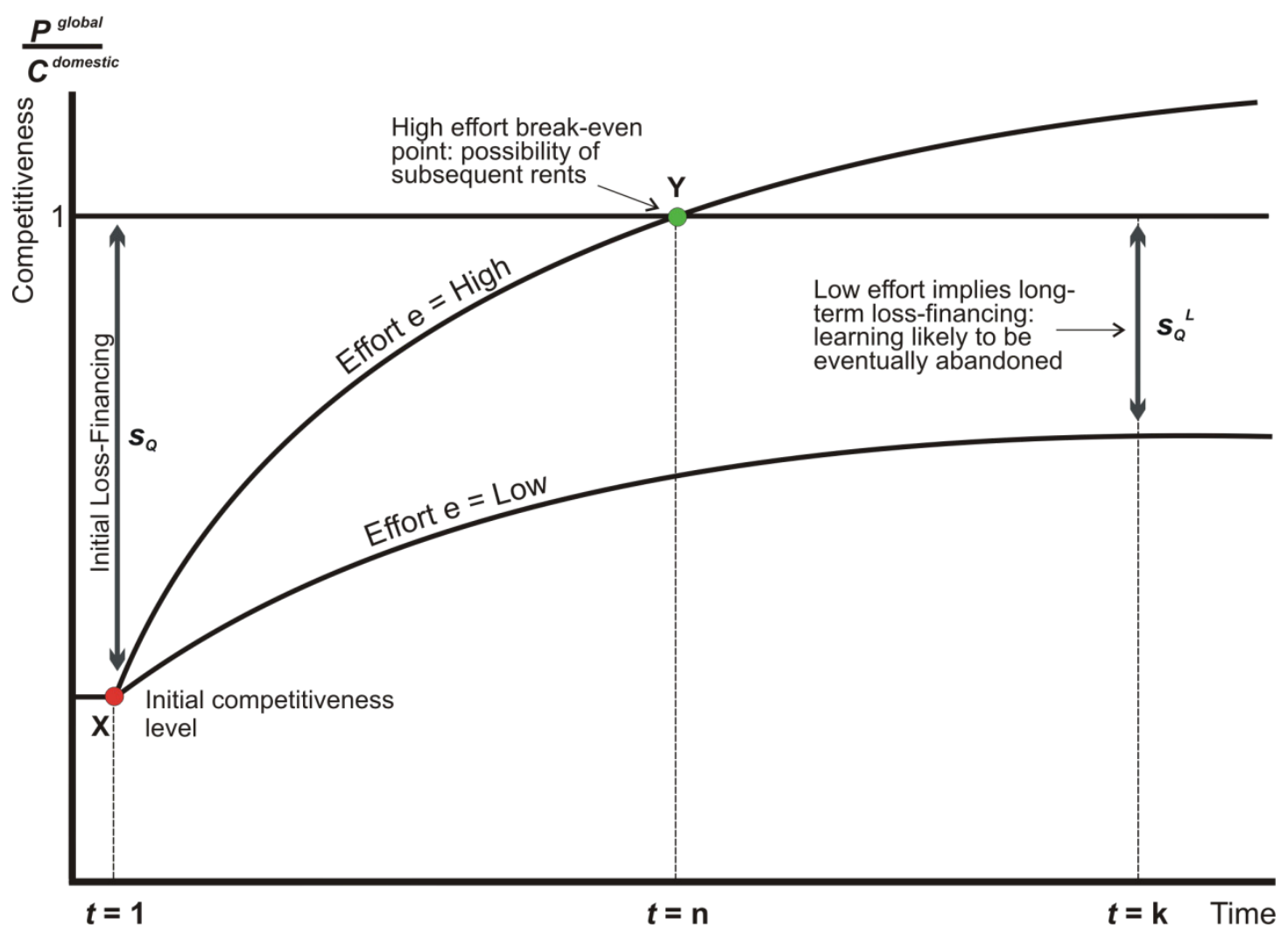

Source: Khan (2013: Figure 2)

Figure 2 Effort Levels and the Viability of the Learning Process

Public policies for technology acquisition in developing countries have responded to this and other contracting failures. One component of most technology acquisition strategies is that states directly or indirectly provide the financing $s_{Q}$ required for the learning-by-doing to commence. When public policy does this, it effectively provides a 'learning rent' to the firm. However, as in the case of private financing, the learning rent is only likely to succeed if by design or accident, the policies create not only opportunities but also compulsions for firms to raise their competitiveness by putting in a high level of effort in the development of organizational capabilities. Without a set of credible conditions on the allocation and withdrawal of subsidies (the rent allocation and management conditions), the outcome is typically a low effort learning strategy on the part of firms, and competitiveness is often never achieved. Thus, with public financing, a different set of incentives and enforcement capabilities come into play, but the underlying problem remains very similar. On the one hand, the state has a wider range of financing instruments and associated enforcement tools than the ones available to private financiers. On the other hand, public financing and policy-induced rents are subject to the rent seeking activities of powerful economic organizations that now have the incentive to spend time and resources to 'politically' protect their rents. We know that some countries have managed to achieve dramatic outcomes through public technology acquisition strategies while others have not. Our contention is that 
by understanding the different components of this problem and designing policies that are likely to work better in the context of specific political settlements, the probability of success can be improved. In any case, the alternative route of attempting to encourage private contracting to finance learning is likely to be even more difficult given the governance environments in most developing countries and the economic characteristics of the learning process.

The apparently short-sighted rent protection strategies of firms receiving learning rents can be better understood if we keep in mind the limited prize that is available by achieving competitiveness. The social benefit to a country of developing national organizational capabilities can be large because of spillovers and clustering effects. However, for the individual firm receiving a learning rent, there is often a strong incentive compatibility problem in putting in high levels of effort to achieve competitiveness. The firm is very likely already receiving enough rents through the policy mechanism to achieve a normal rate of return for the key stakeholders. Its prize for achieving a higher level of organizational capability is that it will lose its learning rent and instead earn a similar normal profit through the tougher route of production in an uncertain and harsh market environment. Given this adverse incentive, it is not surprising that firms will often use their ingenuity and effort in rent-seeking activities to prolong the period of support or to postpone the withdrawal conditions. The result is 'satisficing' behaviour by many firms receiving support for learning, where management and key stakeholders within the firm are happy to continue business as usual and exert most of their creative effort in ensuring that the status quo continues. Of course, in the long run this is not a sustainable strategy, but the long run rarely constrains economic decisions. Successful catching-up strategies have to rely on more than the natural incentives of managers, owners and other stakeholders to grab the opportunity provided by the rent to try and achieve long-run competitiveness. Higheffort learning strategies require effective short to medium-term compulsions on decision-makers in firms to direct their time and effort into developing productive organizational capabilities. This involves some combination of measures to block unproductive rent-seeking activities and imposing conditions on the allocation of rents to compel high levels of effort in learning. This is precisely why the interface shown in Figure 1 between the rent allocation conditions required for the success of a policy and the rent seeking strategies of the relevant organizations is so important.

\section{Institutional Problems of Ensuring Effort in Learning}

The interface between the rent allocation requirement of particular policies and the rent-seeking strategies of organizations is not simple because the outcome depends on non-linear interactions between several variables. The underlying enforcement success or failure has elements that are similar to principal-agent problems that can result in breakdowns in team effort or in the operation of credit markets (Alchian and Demsetz 1972; Stiglitz and Weiss 1981; Shleifer and Vishny 1997). However, here broader political economy issues are relevant because the state is allocating rents and the political ability or otherwise of the state to enforce credible conditions for effort becomes salient. This raises issues that go beyond asymmetric information. Rent seeking is now based on the mobilization of organizational and political power and can determine the likelihood of capturing or protecting particular rents without any asymmetric information. In particular, the political power and links of economic organizations and their organizational capabilities can affect the possibility of 
enforcing effort-inducing conditions on the allocation of particular incremental rents. The problem is that the effect of a rent allocation policy depends not just on the details of the formal rent allocation instrument, but also on its appropriateness for solving the learning problems of firms, on the capabilities of the agencies enforcing it and the political settlement that describes the relative power of the organizations involved. The effect on effort is the outcome of an interaction between these variables that determines the actual conditions of rent allocation and withdrawal, and these determine the real incentives and compulsions of firms to put their effort into productive capability development or unproductive rent maintenance activities. The critical 'variables' that determine the level of effort firms put into the learning exercise to raise their productive capabilities are listed in eq. [1]:

$e=f(F I, G A, F S, P S)$

Effort $e$ is defined as the intensity with which organizational learning through experimentation is being carried out, to raise firm-level productivity. The higher the level of effort, the steeper the convergence to global competitiveness levels in Figure 2. FI describes the specific financing instrument through which the learning rent is delivered. This is broadly defined as any policy instrument that directly or indirectly allocates rents to firms with a possible effect on their learning strategies. The financing instrument is the immediate policy variable that formally defines how the rent should be allocated and defines the formal terms and conditions for withdrawal and the formal responsibilities of the different parties. The formal allocative rules defined by the financing instrument FI may of course not correspond very closely to the actual allocation and management of rents, which may happen largely in response to political pressures and mobilizations, often operating informally. These informal modifications are hugely important and their nature and extent depends on the interaction of the financing instrument with other variables in the function. $G A$ describes the capabilities of the governance agencies that monitor and enforce the conditions implicit in the operation of the financing instrument. The enforcement of the formal rules implicit in each instrument can vary widely depending on the enforcement capabilities of the agencies responsible. FS describes features of the firm structure, referring to characteristics of the firm(s) being supported that are relevant including size, initial productive capabilities, political links and the type of markets (competitive or otherwise) in which they operate. PS is the political settlement which describes the relative bargaining power of the different types of organizations affected by the operation of the policy. The function $f$ is not a differentiable mathematical function, and the variables in this function are unlikely to have additively separable effects. Rather, each of the variables has an effect whose magnitude and even sign can depend on the values of the other variables. This non-linear interdependence makes the political economy of industrial policy particularly interesting.

\section{Financing Instruments}

In the industrial policy strategies of many developing countries in the 1960s and 1970 s, very significant learning rents were typically allocated to broadly defined sectors. The financing instruments used included tariff protection to raise domestic prices of particular products thereby providing rents to domestic firms in protected sectors, export subsidies, tax breaks, low interest credit, often from state-owned development banks and subsidized input prices, including utilities and infrastructure. There are important differences in the details of the design of each of these 
instruments from country to country. However, the general feature of these policies was that a significant portion of these rents were allocated ex ante, that is before the firm had established competitive capabilities, and the rents were significant in their scope (in terms of the numbers of sectors and firms supported). A common feature of these policy choices was that the formal pattern of rent allocation, combined with the distribution of power in the political settlement, created strong incentives for recipient firms to spend time and effort in rent-seeking activities to protect the rents once they had been allocated. Very few developing country states had the political capability to enforce the formal conditions on rent allocation that would compel high levels of effort, such as making the rents time dependent or their allocation conditional on performance. In many cases states did not even try to formally define rent allocation conditions, while in the few successful industrial policy states, early successes in attempts at rent allocation resulted in greater formalization of conditions over time.

This was not just an oversight in the less successful industrial policy states. No country began its technology acquisition policies with a complete map of what needed to be done. In the successful countries, trial and error in policy formulation resulted in formal financing instruments moving in the direction of better-defined formal conditions precisely because productivity-enhancing rent allocations were successful. The political and bureaucratic elites in many developing countries where industrial policy was performing poorly were perfectly aware of the problem at a very early stage but in these countries formal policy did not evolve in the direction of greater effectiveness, precisely because the relevant agencies knew that movements in that direction would not be enforceable. For instance, in India, the Dutt Committee recognized by the mid-1960s that the licensing regime that was directing rents to infant industries was primarily helping a small group of large firms who were capturing these rents on their own terms (Government of India 1969). But the politics of responding to this effectively was not simple. To the extent that responses were attempted, they were often blunt and counterproductive. Thus, in India, one response was Indira Gandhi's Monopolies and Restrictive Trade Practices Act (MRTP) of 1969 which set asset limits on the holdings of large business houses that were thought to have unduly prospered under the licensing regime. The new act was largely punitive, was not properly enforced and had little effect on actual levels of concentration. Significantly, it did not seek to address the problem of rent management to achieve better outcomes. The state did not try to set new conditions for achieving competitiveness by changing the broad contours of the policy, including the choice of supported sectors and firms, even though the necessity of such changes was explicitly recognized by the Dutt Committee.

In other words, the failure to move in the direction of better rent management, at least in India in the 1960s, cannot be attributed to ignorance. However, there may have been missed opportunities of a more complex sort. The problem was that the current financing instruments allocating learning rents were giving significant ex ante rents to broadly defined sectors and it was difficult to exclude large business houses from these rents. Enforcing effective conditions on this financing instrument was clearly beyond the capabilities of the Indian state of the time given the political settlement and it did not attempt to move in that direction. However, other financing instruments may have been more successful and some insights into what may have worked became clearer with the experiences of the 1980s. But thinking through to those options would require a much more open and interactive analytical framework 
incorporating the effects of the political settlement in assessing policy options. Only in this sense were opportunities of policy reform missed at that time.

Similarly, widespread public disapproval of state supported accumulation and technology strategies emerged in Pakistan in the late 1960s as a result of the concentration of wealth in the hands of Pakistan's 'twenty-two families'. The weak control over the rent management process led not only to a very high level of wealth concentration, many of the industries that were emerging were not approaching global competitiveness and had the character of industries protected for cronies. Some real capabilities were undoubtedly developed, but the failure of any significant sector to reach global competitiveness undermined the political support for these strategies. The result was widespread nationalizations in Pakistan and the newly created Bangladesh in the early 1970s under Bhutto and Mujib respectively. The nationalized industries were even closer to political power and therefore even more able to distort rent allocation and less likely to put in high levels of effort in learning. This was the prelude to the abandonment of learning strategies and the transition to liberalization.

The types of formal financing instruments used by states are an important determinant of the incentives and compulsions facing firms not only because the formal rent allocations are different, but also because the informal modifications through rent seeking and resistance may be different because different types of organizations are selected or self-select themselves given the incentives. For instance, monitoring requirements are very different depending on whether the learning rents are available 'ex ante' (before success is established) or promised 'ex post' (after success is established). The typical patent based Schumpeterian rent that creates incentives for innovation is usually available to successful innovators ex post. For rents allocated ex post, the public monitoring requirements are less demanding and the institutional requirement is mainly to determine the period of ex post rent protection, which primarily determines the magnitude of the prize allocated to the successful innovators (Khan 2000a). Even if rents are only available as ex post prizes, they can still help to make the financing of innovation more viable, because innovators can now offer risktaking investors higher returns in the future, thereby getting access to longer periods of low-interest or zero-interest financing. However, some Schumpeterian rents may also be allocated ex ante by public policy, for instance as subsidies to universities or to industries in the form of innovation grants. These ex ante rents require much closer monitoring to ensure progress is being made at different stages of the innovation cycle so that support can be withdrawn and losses minimized if progress is unsatisfactory.

In contrast to Schumpeterian rents, learning rents are typically provided ex ante (for instance through tariffs on imports or the provision of low cost credit). Unfortunately, large programmes granting significant learning rents ex ante have been associated with low effort in learning in many cases. There are exceptions in countries where the political settlement allowed the state to monitor, manage and withdraw rents from significant economic organizations. Most developing countries did not have state organizations or political settlements that had these characteristics, and as a result these types of financing instruments performed poorly. However, there have been interesting cases of successful technology adoption in countries that did not do well with ex ante financing instruments. In the cases of success, the financing often involved the allocation of a significant part of the rent ex post, after substantial success in learning had been established. If the financing instrument allocated some of 
the rent ex ante but reserved significant rents as a prize ex post, conditional on the achievement of competitive success, these conditions could help to self-select firms that believed they could make the productivity jump as well as creating strong compulsions and incentives for high levels of effort in learning. In addition, if the delivery of the ex post rents was sufficiently large and credible, firms engaged in learning could also raise financing on viable terms from investors in the same way as innovators aiming for Schumpeterian rents can raise money for financing innovations.

In the 1980s a number of sectors in South Asian countries made significant progress in technology adoption and in developing organizational capabilities for competitive production. Far from being associated with liberalization, many of these successes were associated with new types of policy-induced rents and rent allocation mechanisms that worked much better. The interesting feature of the new policy environment was that the old financing instruments based on large-scale ex ante financing were gradually phased out and new forms of support emerged, many of which provided a significant part of the learning rent as a prize for success ex post and targeted rents to more narrowly defined sectors or even to individual firms.

Examples include the rents offered by the Indian state to Suzuki to participate in the Suzuki-Maruti joint venture agreement signed in 1982. Most of the learning rent in this case was accessible ex post in the form of access to the protected Indian automobile market which still had tariffs in the region of 85 per cent. But to be able to sell in this protected market, Suzuki first had to make the Maruti-Suzuki car and it had to make it with 60 per cent domestic content within five years. This meant Suzuki had to make a significant investment in improving the organizational capabilities of Indian Tier 1 and Tier 2 component producers to meet the domestic content target and yet produce a car that would be of higher quality than existing Indian cars like the Ambassador. There were additional reasons for not compromising on quality, including the reputation risk for the global Suzuki brand. The design of the financing here clearly created strong incentives and compulsions for effort because Suzuki had no interest in drawing the process out and every interest in completing it quickly. Moreover, there was a very strong likelihood that without fulfilling the domestic content requirement the company could be excluded from the ex post rent. Exclusion from the domestic market for contract violation was a condition that could be plausibly enforced on a single foreign company with no domestic political alliances given India's governance capabilities and political settlement at the time. Not surprisingly, the result was a very successful transfer of organizational capabilities, with the rapid development of a broad group of component manufacturers who later became the foundation of a globally competitive Indian automobile industry.

Another example was the garment industry takeoff in Bangladesh in the 1980s which was based on the MFA (Multi-Fiber Arrangement) providing ex post rents to producers in Bangladesh provided they achieved sufficient competitiveness to begin to export. The MFA restricted imports into the USA from established garments exporters and this enabled quota-free countries like Bangladesh to temporarily enjoy rents in these markets as a result of the slightly higher prices at which they could sell. This was an ex post rent because the prize could only be captured by firms that had already developed enough organizational capabilities to be able to export. The availability of the prize enabled the first garments firms in Bangladesh to raise money for investing in capability development. Here too there were interesting innovations, 
including an on-the-job training programme for managers from the Bangladeshi company Desh that was conducted in the South Korean plant of Daewoo. Daewoo undertook to host the Bangladeshis at its own expense, to be repaid by the Bangladeshi company with a percentage of its sales revenue. This financing arrangement for transferring organizational capabilities created strong compulsions on both sides to put in high levels of effort as the costs of all parties went up with a loweffort strategy. The result was a very successful transfer of organizational capabilities. Desh became the pioneer of the garments industry in Bangladesh, and contrary to the first-mover disincentive story, it encouraged and allowed its managers to leave and set up new garments firms so that clustering could rapidly happen. Both these examples are discussed in greater detail in Khan (2013).

The general point to be made here is that while the traditional financing instruments providing ex ante rents did not work in South Asia, the experience of the 1980s shows that other types of financing instruments did work in successfully financing the development of new organizational capabilities. These capabilities in turn allowed the transfer and adaptation of technologies new to these countries. Indeed both the automobile sector in India and the garments and textile sector in Bangladesh played an important role in driving economic growth in these countries for more than three decades since the 1980 s.

\section{Governance Agencies}

Governance agencies are the bureaucracies within the state that are charged with the management of policies including the allocation of the relevant rents. The formal technical capabilities of these agencies to monitor and enforce these allocations clearly matter. Relevant agencies may include central banks, development banks, fiscal agencies and planning commissions charged with monitoring and implementing the allocation of rents associated with particular programmes. However, the actual power of governance agencies depends not just on their technical capabilities and training but also on the political settlement of which they are a part. Governance agencies are organizations and the relative power of these organizations relative to others is an important aspect of the political settlement. The technical capabilities of governance agencies (described in this variable) and the relative power of these organizations relative to others (as described in the political settlement variable) jointly determine the ability of governance agencies to enforce particular sets of rent allocation conditions.

The governance agency that is relevant depends on the financing instrument. For instance, if rents are allocated to firms in the form of cheap credit from industrial banks, the relevant governance agencies are the managements of the banks and the agencies the banks in turn rely on for the enforcement of their contracts (like bankruptcy courts). Do these agencies collectively have the capability to monitor loans effectively; do they have the power to withdraw loans if firms are failing to adhere to agreed conditions? Similarly, if rents are allocated in the form of subsidies, the relevant governance agencies are the ones responsible for administering the subsidies. Do they have the technical capabilities for monitoring performance and withdrawing the subsidies if necessary?

Technical capabilities alone clearly do not ensure that enforcement will be effective. The distribution of power across organizations in the political settlement and the types 
of rents that are being allocated through the financing instrument jointly determine the degree of enforcement that is achieved. The same governance agencies may be quite effective in enforcing a rent allocation that involves imposing conditions on relatively weak organizations but may fail when enforcing a slightly different policy that requires them to discipline organizations that happen to be powerful within the current political settlement. For instance, a policy of granting temporary export subsidies to firms using new technologies could create compulsions for high levels of effort if the affected firms had no means of prolonging these subsidies but not if they had the political ability to override the time limits using their political alliances. Industrial development banks are likely to have higher levels of credibility for enforcing threats of capital withdrawal from failing firms if the firms do not have powerful political allies and the bank is supported by a strong president rather than if the bank is operating in a context of divided political authority where powerful political factions can prevent the enforcement of discipline on their client business houses. The contribution of the governance agency to the achievement of a high-effort outcome therefore depends not just on the technical competence of the relevant agency but also on the financing instrument that defines the distribution of rents and the political settlement that defines the relative power of the affected organizations: another example of the non-linear interaction between these variables.

\section{Firm Structure}

The outcome of a particular policy framework also depends on the characteristics of the firms that are benefiting from a learning strategy. A number of features of the firms targeted by policy may be relevant. What is their initial productive capability, how are they connected to different types of political organizations, how does this affect their bargaining power to protect rents, what kind of markets do they operate in and are there competitive pressures coming from these markets to raise their productivity? These and other features of the firm structure can affect the 'fit' between the expected outcomes of a formal rent allocation policy and its actual outcome in terms of the effort put in by firms in raising productive capabilities. Once again, there are many non-linear interactions to be aware of that can produce unexpected outcomes if we are not careful.

The productive capabilities of firms can have two contradictory effects on their rent capture strategies. First, more productive firms have more resources to invest in rentseeking activities. This increases the likelihood that these firms will be more able to protect any incremental rents they get. On the other hand, productive firms that are already close to the competitiveness frontier may find that putting their effort into becoming competitive may be a safer and more viable strategy than focusing on rent protection alone. In contrast, for firms that are far away from the competitiveness frontier, high effort in developing the appropriate organizational capabilities only makes sense if they can be assured of long-run support for learning and if the easier strategies of rent protection are ruled out by effective limits on their rent-seeking activities. By definition, most firms in developing countries initially do not have high levels of technological and organizational capabilities (this is why the country is still developing). Most firms still have to learn how to learn before they actually start learning (Stiglitz 1987). This creates adverse incentives for many firms to invest in political connections because if they had to rely solely on their productive capabilities they would be very vulnerable. Older or larger firms, particularly when they are not very productive are more likely to be well-connected to political organizations and 
their prosperity is likely to be dependent on these connections. Consequently it may be difficult to discipline such firms in a context where significant learning rents are being provided by the state. One of the advantages of financing mechanisms that provide significant ex post rents is that this induces a degree of self-selection in the firms taking up these schemes. A firm that has little chance of becoming competitive in a new technology is unlikely to participate in a scheme that requires it to invest upfront in organizational capabilities based on the promise of significant ex post rents.

The political connections and networks of firms are very important for explaining their bargaining power in protecting their rents or subverting conditions attached to these rents, but these connections cannot be read off from their economic characteristics. This is why we need independent data on the overall political settlement which describes the relative power of different types of organizations. The political settlement variable has an interactive effect in determining why apparently similar types of firms may respond differently to similar types of financing instruments. For instance, the modern manufacturing sector in both Pakistan and South Korea in the 1960s was dominated by a small number of large diversified holding companies that each included plants in different manufacturing sectors. In both countries, public policy provided learning rents to these conglomerates to acquire new technologies and move into exports through similar financing instruments like domestic market protection, subsidized credit, and export subsidies. However, high levels of effort could not be achieved for firms of this type in Pakistan but were achieved in South Korea. To a significant extent this was because large conglomerates in Pakistan acquired the political capacity to protect their rents from threats of withdrawal in a way that South Korean chaebols could not. To understand this we need to look at the relationships between the firm structure and political organizations within the context of a political settlement. In Pakistan, there were many political suborganizations that were not under the centralized control of the ruling coalition, despite the ruling coalition being a military-led government in the $1960 \mathrm{~s}$, just as in South Korea. Behind the formal structure of a unified ruling coalition, the Pakistani political settlement described a distribution of organizational power that was significantly fragmented. Many political and bureaucratic organizations were independently powerful and they could deploy their power to benefit themselves independently of the wishes of the President.

The consequence was that firms in Pakistan that wanted to protect their rents could easily make arrangements to share rents with one or more of these political or bureaucratic sub-organizations. This involved kicking back some of their subsidies to these lower-level organizations and in exchange the latter would assist by effectively protecting their rents. This arrangement benefited the firm and their allied political and bureaucratic organizations but adversely affected the overall industrial strategy and the net social benefits of the country. The interface between the firm structure and the specific political settlement meant that financing instruments that provided a significant part of the rents ex ante could not be effectively disciplined in Pakistan. Not so in South Korea. The large chaebol were the descendants of Japanese companies and after the defeat and departure of Japan, these companies enjoyed little popular sympathy or support. Moreover, even if the chaebol had some legitimacy, they would have found it very difficult to make similar political connections. The ruling coalition in South Korea was differently structured, and could impose its authority on its own lower levels. Political organizations outside the ruling coalition 
had very limited power to protect the rents of firms. This meant that firms receiving rents would have to satisfy the calculations of the highest authorities to retain their rents. The highest authorities had no incentive to tolerate rent capture by organizations that were not enhancing productivity. This is because a secure ruling coalition that could take a view over several years would always find more productive organizations more attractive to support because the latter could provide greater benefits over time, whether legally in the form of taxes or illegally in the form of kickbacks. The threat of rent withdrawal from low-effort firms was therefore credible in South Korea and because it was credible, this threat rarely had to be used. High levels of organizational effort were always forthcoming (Khan 1999).

Although Taiwan is often loosely included in the 'East Asian' model, its firm structure and financing instruments were quite different from South Korea in the 1960s and 1970s. In Taiwan, financing instruments allocated rents to much smaller firms and once we look at Taiwan's political settlement, it is possible that a strategy of building up very large conglomerates may have failed at that time. The Kuomintang (KMT) was a foreign political force in Taiwan, having been forced there after their defeat in mainland China at the hands of Mao's forces in 1949. Given its external origins, the KMT was clearly unwilling to allow domestic economic conglomerates to become too big because they may well have used their economic power to challenge the political authority of the outsiders. In any case, large Taiwanese conglomerates may have been difficult to discipline in this political settlement. Fortunately for Taiwan, the financing instruments used by the government in its strategies of technology acquisition focused on smaller firms in high technology sectors. These firms had sufficient organizational capabilities to be interested in investing in productive capacity development, but were politically unable to link up with sub-organizations within the KMT or to challenge its authority entirely. As a result, the Taiwanese state's ability to enforce discipline in the form of conditions on its rent allocation decisions was not impaired. The interesting counterfactual is whether countries like Pakistan and India may have fared better if they had designed support schemes for smaller firms who may have found it more difficult to capture policy in the way in which the 'twenty-two families' of Pakistan or the big business houses of India did (Wade 1988; Amsden 1989; Wade 1990; Whitley 1992; Khan 1999; Khan and Blankenburg 2009).

The pressure on firms to invest in productivity growth is likely to be enhanced if some part of their activity is in competitive markets. Firms that are exporting, even with subsidies, will soon find that without productivity growth, the existing level of subsidy will be insufficient for their continued survival. In contrast firms producing for protected domestic markets or with considerable market power may ignore productivity growth for much longer. This is yet another reason why countries with political settlements where large established firms have many links with political organizations should focus their financing on smaller firms operating in more competitive markets. Apart from the greater difficulty such firms may find in establishing political linkages, their market operations can add to their compulsions for enhancing organizational capabilities. Market competition is not enough on its own, because learning still requires rents and the rents dampen competitive pressures for a while. This is precisely because at existing market prices these firms could not enter production at all given their current capabilities. But some market exposure can reduce the challenges of monitoring and enforcing conditions to compel high levels of 
effort. Of course, for some products, scale economies mean that a small-firm strategy is implausible. In these cases, policy design has to be aware of the difficulties of disciplining large well-connected firms. Compensatory measures to prioritize the strengthening of governance agencies may be a partial solution. In some cases the answer may be to delegate the governance of learning rents to more independent external agencies like industrial banks. If the management of the industrial bank is less accessible to political pressure, the credibility of withdrawal may be high enough to compel learning. Finally, in some cases, ex post rents can work, as in the case of the Maruti-Suzuki partnership in India. Here, the instrument was the offer of large ex post rents conditional on the transfer of organizational capabilities to domestic component producers. This led to a large foreign firm self-selecting to participate in the joint venture because it had enough organizational capabilities to believe it could transfer the requisite capabilities to Indian firms and thereby capture the ex post rents.

\section{The Political Settlement}

The political settlement describes the distribution of organizational and bargaining power across economic, political and bureaucratic organizations in a society (Khan 1995, 2010). The relative power of different organizations develops in path dependent ways, but at any point in time, the description of the political settlement in a country is an important 'independent variable' in an analysis of the outcomes associated with incremental policy changes. Each incremental policy change allocates incremental rents to different organizations on specific conditions. The political settlement is relevant for understanding the likely outcomes of the policy because it describes the capability of organizations to challenge or distort the conditions of rent allocation implicit in the formal policy. The outcome in reality may therefore be far removed from what the formal policy set out to do, because the rent allocation that the formal policy required or the conditions of evaluation and enforcement that it depended on could not be enforced in that political settlement.

Rent seeking by powerful organizations refers not just to their expenditure of resources in order to influence bureaucrats and politicians. More importantly, it refers to their political activities through which they develop their holding power and construct coalitions to enhance this holding power. Holding power describes the ability of an organization to hold out in prolonged conflicts and it is this capability that determines the probability of winning. Holding power depends not just on the resources the organization can deploy but also on its power to mobilize support. In a developing country this depends on its links with powerful patron-client political organizations. Rent seeking contests between organizations have characteristics of 'chicken games' in game theory where a prize can be distributed in two very different ways but each requires one side to win and the other to accept defeat. There are thus two Nash equilibria but which one emerges depends on the perceptions of each side of the holding power of the other. It is only when they each think they can win or if they miscalculate the holding power of the other that a conflict ensues which is costly for both sides. Conflicts of this type end when a new distribution of holding power is accepted by both sides and the distribution of rents reflects this distribution.

The political settlement describes the structure of holding power as it has evolved and helps us to understand some of these rent conflicts better. In many developing countries, there are many competing political organizations each based on mobilizing supporters using patron-client politics. The more such political organizations exist, the 
easier it is for economic organizations to buy themselves holding power at a relatively low price. When political organizations are at the same time powerful and fragmented, economic organizations, certainly the bigger and more resourceful ones, are likely to find it easy to purchase holding power. On the other hand when the ruling coalition includes the most powerful political organizations and the higher levels of the ruling coalition have effective control over the lower levels, economic organizations can find it much harder to buy themselves holding power and protection at an acceptable price. These are the types of differences in the political settlement between South Asia and East Asia in the 1960s that we have already referred to.

We have already seen how differences in political settlements can explain why apparently similar governance agencies, firm structures and financing instruments can result in very different outcomes across countries. South Korea and Pakistan in the 1960s used fairly similar strategies of providing cheap long-term bank credit and export subsidies to large conglomerates in export-oriented sectors. But the outcomes were significantly different because their political settlements were different and the critical conditions that were required for inducing effort through rent allocation could be enforced in one case but not the other (Khan 1999). Indeed even the evolution of formal policy was affected in South Asia. As we saw in the case of the Dutt Committee report in India, an adverse combination of a particular political settlement and a financing instrument made policy-makers give up on evolutionary developments of formal policy which they knew were pointless given the holding power of powerful economic organizations. Differences in the political settlement can also help to explain why effective financing instruments and governance agencies have differed so significantly across successful catching-up countries. South Korea, Taiwan, China and Malaysia display significant differences in their catching up strategies and instruments. The general framework outlined here can explain why a different ensemble of instruments and agencies would be effective in inducing higheffort learning given the differences in their structures of firms and their political settlements (Khan 2000b, 2008; Khan and Blankenburg 2009).

\section{Interdependencies Affecting Policies for Learning}

Effective learning strategies require as a precondition an ensemble of conditions to ensure high levels of effort. This is not always easy to achieve, and the failure to address or even understand these problems has been responsible for the abandonment of many learning and technology acquisition strategies across developing countries. An important reason why effective policies have been difficult to devise is because the variables in eq. [1] have interdependent non-linear effects on effort. This means that the best financing instrument, for instance, may depend on the type of political settlement and firm structure that a country has inherited. The same instrument may be ranked lower than others in its effects on effort in a context with a different political settlement and firm structure. As a result, there is no single set of financing instruments and governance arrangements that characterize all successful catching up countries. It also follows that it is not possible to simply imitate the policies or governance structures of more successful developers. 


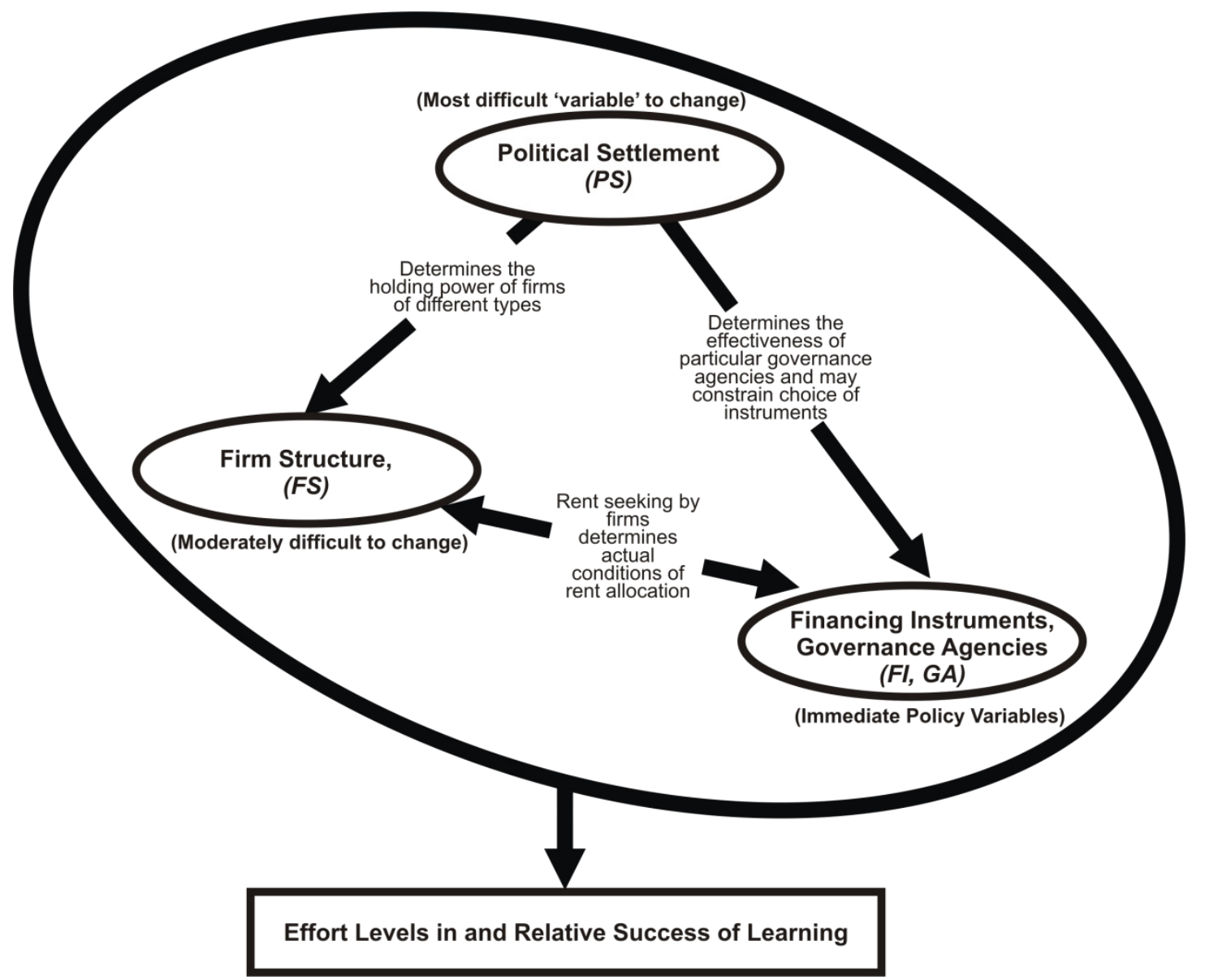

Figure 3 The Interdependence of Variables Determining Effort

Some of the interdependencies between the variables affecting effort in eq. [1] are shown in Figure 3. From a policy perspective, it is important to distinguish between variables that are very difficult to change and which can therefore only be the targets of policy in the long term and variables that are easier to change and are more immediate policy variables. The variables that are most difficult to change are effectively 'exogenous' in the short term and policy is likely to have to accept them as given. In Figure 3, the political settlement, $P S$, appears at the top of the list as it is likely to be the variable that is most difficult to change. However, even the political settlement can of course change, and it can change as a result of political policy, for instance through the organization of new political coalitions or movements. Indeed, if the political settlement is very unfavourable for organizing any serious process of learning, the only meaningful policy would be to begin the process of changing the political settlement. Of course, this is a process with unpredictable outcomes and one that only political organizations with legitimate leaderships can hope to achieve.

Next in terms of difficulty of changing is the firm structure, FS. The overall firm structure may be very slow to change, but policy can still select different groups of firms to support, so the firm structure that is targeted by policy is not necessarily fixed. Finally, the variables that are usually the most direct targets for policy appear at the bottom, the financing instruments, FI, and the associated governance agencies, $G A$, though governance agencies too may not necessarily be easy to set up or change. However, even if the policy relevant financing instruments are the only entry points 
for most policy purposes, the most appropriate financing instruments cannot be identified without at least identifying the other variables and the implications for rent management in the context defined by those variables. What is ruled out is the hope that these variables are 'additively separable', so that good financing instruments or effective governance agencies can be identified independently of a political economy analysis of the interactions between these variables in particular contexts.

\section{Policy Conclusions}

The complexity of the relationships between financing instruments, governance agencies, firm structures and political settlement can explain why many plausible strategies of learning often failed. In many developing countries, strategies of learning and catching up between the 1950s to the late 1970s failed because while many new sectors and firms emerged, the progression to global competitiveness was too slow. Financing costs multiplied and found expression in growing budget deficits or in growing non-performing assets of state-owned industrial development banks. Eventually, many of these strategies were abandoned, partly because of internal reasons, partly because of the global intellectual and policy consensus in favour of cutting back subsidies in developing countries in the 1980s.

An intriguing question is whether the countries which eventually abandoned learning strategies could have done significantly better had they followed a different approach for identifying and addressing the market failures that affected their learning. India and Pakistan (of which Bangladesh was a part at that time) attempted ambitious 'East Asian' industrial policies but without the political settlements that would allow effective compulsions for high levels of effort. Large, relatively well-connected firms benefited from different types of 'learning rents' but managed to buy themselves sufficient protection from different factions to prevent threats of subsidy withdrawal to be credible. The result was significant industrialization but slow growth towards global competitiveness levels (Khan 2000b).

Figure 3 suggests that there could have been two types of responses to this problem (apart from abandoning the strategy). The first and more ambitious response would have been to use policy to change aspects of the political settlement that were preventing the imposition of credible compulsions on the firms receiving rents for learning. The political settlement may be difficult to change rapidly, but it is always changing endogenously. Could the relevant aspects of the political settlement that constrained growth have been addressed by political entrepreneurs if they had a better understanding of the constraints? This is a tempting idea but it is not a direction in which we should readily go without understanding the dangers. Political settlements are complex systems like biological organisms or weather systems. We can understand and describe the macro-level features of biological organisms or weather systems and this may help us to design micro-interventions like medicines or when to take out our umbrellas. However, we are far away from understanding these complex systems well enough to attempt to change a biological organism or a weather system into another with predictable results. The same is true of political settlements. A political intervention like a new party or administrative decentralization will change the distribution of power across organizations over time, but we may be surprised at the direction of the evolution. To say the least, attempts to change the political settlement are highly risky and the results are too uncertain for this to be policy advice 
that can be given with any confidence. Nevertheless, it is equally clear that political movements and struggles as well as economic changes that are going on all the time are constantly changing the political settlements of countries.

A second and apparently less ambitious response may be more appropriate. This would be to focus on policy choice, but to do so with a fuller understanding of the non-linear relationships between the relevant variables. The response would be to consider other policy mechanisms for supporting learning in the context of the existing political settlement, and feasible changes in governance agencies and firm structures such that the incremental rents effectively created a combination of incentives and compulsions for learning. We know that in the 1980s a number of developing countries that had not performed strongly with 'traditional' industrial policy nevertheless achieved effective learning outcomes in some sectors. They did this because (largely serendipitously) they attempted financing instruments, which given the firm selection and the technologies they were acquiring, resulted in credible incentives to enhance or transfer organizational capabilities in these sectors. The policy challenge in developing countries is to do this matching of compatible combinations of variables in a more deliberative and purposive way so that we do not have to wait for the next lucky accident to happen.

Much of the policy discussion on technology policy identifies a variety of contracting failures but the critical contracting failures that constrain the development of competitive organizations have often been ignored. The starting point for any policy analysis of technology acquisition is to understand that almost every effective learning strategy must involve a component of rent management for developing appropriate organizational capabilities. For this, it is not enough to create rents to support learning, we have to be sure that these rents come with appropriate and enforceable conditions that create credible compulsions for effort. Here a background understanding of the current macro-level distribution of power across organizations (the political settlement) helps to identify the clusters of firms that are politically powerful and therefore likely to present the most serious challenges for effective rent management. This does not mean that these firms should be avoided by technology policy, but it does mean that technology policy has to give particular attention to how issues of effort and rent withdrawal can be managed for these types of firms. It may be much easier to drive growth with a different set of firms or sectors where the political linkages are less problematic. Indeed, if political stability requires giving something to the politically well-connected enterprises, that should be seen as a part of political stabilization strategies and not technology policy. Even at the height of its reform process, China allowed a number of less efficient public sector enterprises to continue operating and receiving rents, as these enterprises protected employment and distributed rents to important constituencies even if they had no chance of becoming economically viable. These types of redistributive policies are fine as long as we do not confuse them with technology policy. In China policy support for enterprises that could become globally competitive used other instruments and focused on other sectors.

If governance agencies are weak and particularly if the weakness is related to characteristics of the political settlement, then financing strategies need to be considered which further reduce the monitoring and enforcement requirements for governance agencies. For instance, if the political settlement describes a distribution 
of power across political organizations that results in intense political competition between parties and factions, the imposition of hard rent allocation conditions on powerful industrial groups is likely to be difficult as different parties and factions are likely to strongly protect their client businesses. An interesting variant of financing instruments that can significantly reduce monitoring requirements are those providing a significant part of the rents ex post. We have seen a few examples of these in developing countries. These financing instruments are not suitable for all sectors and technologies but they may be for some. The advantages include self-selection of the more appropriate economic organizations to participate in these policies. In addition, this type of financing can create strong internal incentives and compulsions for effort within the firm because it is investing first and relying on the achievement of competitiveness to get the prize of rents later. In some cases, like the Indian automobile and Bangladeshi garments cases that we discussed, the financing instrument also involved a small number of initial participants or even only one, so that the monitoring of the rent allocation conditions was even easier.

Finally, an important general result that can be derived is that the next set of successful financing instruments for successful technology acquisition and learning in the next developing country will not look exactly like any previous ones. This is precisely because of the non-linear interdependencies that we have discussed, which make technology policy so challenging. The framework discussed does not give us blueprints for financing instruments that can be used in different contexts because such blueprints do not exist. However, it goes beyond general recommendations for context-specific analysis. It provides a broad analytical framework for discussing issues and checking the plausibility of a particular set of financing instruments by looking for interdependent relationships that may help or hinder the enforcement of conditions for high-effort learning.

\section{References}

Alchian, Armen A. and Harold Demsetz 1972. Production, Information Costs, and Economic Organization, American Economic Review 62 (5): 777-95.

Amsden, Alice 1989. Asia's Next Giant: South Korea and Late Industrialization. Oxford: Oxford University Press.

Chang, Ha-Joon 1994. The Political Economy of Industrial Policy. London: Macmillan.

Dosi, Giovanni 1988. The Nature of the Innovative Process, in Dosi, Giovanni, Christopher Freeman, Richard R. Nelson, Gerald Silverberg and Luc Soete (eds) Technical Change and Economic Theory, London: Pinter Publishers.

Government of India 1969. Report of the Industrial Licensing Policy Inquiry Committee (Main Report). (Chairman Shri Subimal Dutt). Ministry of Industrial Development: New Delhi. 
Hausmann, Ricardo and Dani Rodrik 2003. Economic Development as Self Discovery, Journal of Development Economics 72 (2): 603-33. Available HTTP: $<\underline{\text { http://ksghome.harvard.edu/ drodrik/selfdisc.pdf }>}$

Hoekman, Bernard M., Keith E. Maskus and Kamal Saggi 2004. Transfer of Technology to Developing Countries: Unilateral and Multilateral Policy Options. World Bank Policy Research Working Paper No. 3332. World Bank: Washington DC.

Khan, Mushtaq Husain 1995. State Failure in Weak States: A Critique of New Institutionalist Explanations, in Harriss, John, Janet Hunter and Colin M. Lewis (eds) The New Institutional Economics and Third World Development, London: Routledge.

Khan, Mushtaq Husain 1999. The Political Economy of Industrial Policy in Pakistan 1947-1971. SOAS Department of Economics Working Paper No. 98, School of Oriental and African Studies, University of London. Available $<$ http://eprints.soas.ac.uk/9867/1/Industrial_Policy_in_Pakistan.pdf $>$

Khan, Mushtaq Husain 2000a. Rents, Efficiency and Growth, in Khan, Mushtaq H. and K.S. Jomo (eds) Rents, Rent-Seeking and Economic Development: Theory and Evidence in Asia, Cambridge: Cambridge University Press.

Khan, Mushtaq Husain 2000b. Rent-seeking as Process, in Khan, Mushtaq H. and K.S. Jomo (eds) Rents, Rent-Seeking and Economic Development: Theory and Evidence in Asia, Cambridge: Cambridge University Press.

Khan, Mushtaq Husain 2008. Governance and Development: The Perspective of Growth-Enhancing Governance, in GRIPS Development Forum (ed.) Diversity and Complementarity in Development Aid: East Asian Lessons for African Growth, Tokyo: National Graduate Institute for Policy Studies. Available $<\underline{\text { http://eprints.soas.ac.uk/9853/1/GRIPS.pdf }>}$

Khan, Mushtaq Husain 2010. Political Settlements and the Governance of GrowthEnhancing Institutions. Research Paper Series on Governance for Growth. School of Oriental and African Studies, University of London: London. Available $<$ http://eprints.soas.ac.uk/9968/1/Political_Settlements_internet.pdf $>$

Khan, Mushtaq Husain 2013. Technology Policies and Learning with Imperfect Governance, in Stiglitz, Joseph and Justin Yifu Lin (eds) The Industrial Policy Revolution I. The Role of Government Beyond Ideology, London: Palgrave.

Khan, Mushtaq Husain and Stephanie Blankenburg 2009. The Political Economy of Industrial Policy in Asia and Latin America, in Dosi, Giovanni, Mario Cimoli and Joseph E. Stiglitz (eds) Industrial Policy and Development: The Political Economy of Capabilities Accumulation, Oxford: Oxford University Press. 
Murphy, Kevin M., Andrei Shleifer and Robert W. Vishny 1989. Industrialization and the Big Push, Journal of Political Economy 97 (5): 1003-26.

North, Douglass C. 1990. Institutions, Institutional Change and Economic Performance. Cambridge: Cambridge University Press.

Nurkse, Ragnar 1953. Problems of Capital Formation in Underdeveloped Countries. Oxford: Oxford University Press.

Rosenstein-Rodan, Paul N. 1943. Problems of Industrialisation of Eastern and SouthEastern Europe, The Economic Journal 53 (210/211): 202-11.

Scitovsky, Tibor 1954. Two Concepts of External Economies, Journal of Political Economy 62 (2): 143-51.

Shleifer, Andrei and Robert W. Vishny 1997. A Survey of Corporate Governance, Journal of Finance 52 (2): 737-83.

Stiglitz, Joseph E. 1987. Learning to Learn, Localized Learning and Technological Progress, in Dasgupta, Partha and Paul Stoneman (eds) Economic Policy and Technological Development, Cambridge: Cambridge University Press.

Stiglitz, Joseph E. 1996. Whither Socialism? Cambridge Massachusetts: MIT Press.

Stiglitz, Joseph E. 2007. Making Globalization Work. London: Penguin.

Stiglitz, Joseph E. and Andrew Weiss 1981. Credit Rationing in Markets with Imperfect Information, American Economic Review 71 (3): 393-410.

Wade, Robert 1988. The Role of Government in Overcoming Market Failure: Taiwan, Republic of Korea and Japan, in Hughes, Helen (ed.) Achieving Industrialization in East Asia, Cambridge: Cambridge University Press.

Wade, Robert 1990. Governing the Market: Economic Theory and the Role of Government in East Asian Industrialization. Princeton: Princeton University Press.

Whitley, Richard 1992. Business Systems in East Asia: Firms, Markets and Societies. London: Sage.

Williamson, Oliver E. 1985. The Economic Institutions of Capitalism. New York: Free Press.

World Bank 1993. The East Asian Miracle: Economic Growth and Public Policy. Oxford University Press: Oxford. 